\title{
SCREEN-CAPTURE INSTRUCTIONAL TECHNOLOGY: A COGNITIVE TOOL FOR DESIGNING A BLENDED MULTIMEDIA CURRICULUM
}

\author{
JEFFREY G. SMITH \\ RITA L. SMITH \\ Saint Mary's College of California
}

\begin{abstract}
Online instruction has been demonstrated to increase the academic achievement for post-secondary students; however, little empirical investigation has been conducted on high school students learning from online multimedia instruction in the traditional classroom. This study investigated the knowledge acquisition, transfer, and favorability of secondary students using a teacher's screen-capture instructional technology. A two-group experimental pretest-posttest study was conducted on secondary students enrolled in two computer aided design (CAD) classes. Total scores on the posttests were significantly higher for students in the screen-capture group $(M=9.71)$ than those in the textbook group $(M=7.83), F(1,48)=4.79, p<.05$, partial $\eta^{2}=.09$. Additionally, $88.2 \%$ of the students surveyed preferred learning from the multimedia instruction over written text. This study implies that a teacher's screen-capture multimedia instruction can be used toward establishing a blended learning environment.
\end{abstract}

The climate of educational reform and school accountability places extraordinary demands upon K-12 teachers and administrators to improve student academic achievement. As these academic institutions comply with annual federal and state high-stakes testing mandates, new computer-based instructional technologies are

(c) 2012, Baywood Publishing Co., Inc. doi: http://dx.doi.org/10.2190/EC.46.3.a http://baywood.com 
being considered as possible solutions to increase student achievement and testing outcomes (Kingsley \& Boone, 2008). With the recent proliferation of multimedia devices and broadband networks within K-12 facilities, online multimedia instruction is now viable for the classroom setting. Many secondary schools have begun to augment traditional teaching practices by incorporating online instruction for recovery purposes, remote learning, and teaching alternative curriculums. Three-quarters of K-12 school districts (74.8\%) across the nation have introduced online curriculums and more than half of the remaining districts (15.0\%) are planning to use some form of online instruction in the near future (Picciano \& Seaman, 2009). With this rapid growth of computer-based instruction, online learning appears poised to replace many traditional forms of instruction. Christensen, Horn, and Johnson (2008) estimate that by the year 2019, about $50 \%$ of all high school classes will be delivered online and by $2024,80 \%$ of secondary courses will be online in a student-centric manner.

While many school districts and academic policymakers are assessing online instruction as a replacement for current teaching practices, evidence supporting the effectiveness of the pedagogy is limited. K-12 school districts are increasingly using Internet classes for instruction, yet there is not adequate research indicating whether the instruction is helping, hindering, or having any affect on learning (Figlio, Rush, Yin, \& National Bureau of Economic Research, 2010). Though a 2009 U.S. Department of Education's (USED) meta-analysis claimed, "On average, students in online learning conditions performed better than those receiving face-to-face instruction" (USED, 2009, p. ix), there is admittedly very little data to support these claims within the K-12 environment. The authors of this meta-analysis also stated that caution should be used when generalizing for the K-12 population, as most research on purely online instruction has been conducted with college level students outside of traditional classroom settings.

K-12 classrooms have traditionally relied on textbook content and lecture delivery for instruction. When educational materials are presented by teachers in drawn-out lectures or from a textbook chapter, overall student learning is likely to be minimal (Mayer, 2009). In addition to providing instruction that is uninspiring nor engaging, many teachers rely on instructional practices that do not meet their students' cognitive requirements. Kingsley and Boone (2008) noted that students' difficulties in learning are often attributed to an incompatibility between instructional style and the learners' needs. Compounding this problem, many secondary classroom teachers and academic administrators remain uncertain how to implement new technologies to replace outdated forms of classroom instruction. By relying on technology that is not completely understood, its potential benefits could be attenuated. As noted by Sweller (2005), instruction that is created without anticipating human cognition is likely to be ineffective.

There is considerable uncertainty specifying the type of instructional methodology that would best support today's tech savvy students. Unlike previous generations, today's learners expect to access information from anytime and 
from anywhere (Dale \& Pymm, 2009). With ubiquitous access to online data, the culture of today's plugged-in students is rapidly changing. As noted by Smith (2006), broadband internet access has been brought into schools faster than any other comparable technology. What may have been appropriate for instruction a generation ago no longer feels right in high school classrooms filled with high-speed broadband access, multimedia computers, and students who have grown accustom to constant online access (Cesarini, Sinn, \& Armentano, 2006).

\section{BLENDED MULTIMEDIA LEARNING}

Online learning does not require a physical departure from the classroom or the replacement of traditional pedagogies. As a direct result of the Telecommunications Act of 1996 that authorized the Federal Communications Commission (FCC) to provide America's schools direct access to the emerging information age (Telecommunications Act of 1996), learners can access online multimedia instruction from networked classrooms. Rather than rely solely on face-to-face teaching or remote online multimedia instruction, blended multimedia learning utilizes the benefits of both instructional methodologies. Unlike early forms of online learning that were limited to static text-based instruction, online multimedia learning delivers instructional content combined with words, dynamic images, and audio narration. Blended instruction combines online and face-to-face delivery in a manner where a substantial proportion of content is delivered online in an asynchronous manner (Picciano \& Seaman, 2009). According to the USED (2009), students in a blended learning environment outperform both online instruction and face-to-face teaching. The reasons stated for student academic achievement in these blended learning environments are not clear, but results appear to indicate that learners gain from the added instructional time in the traditional school system, the ability to utilize additional resources available within the classroom, and the physical interaction with fellow classroom students.

\section{SCREEN-CAPTURE INSTRUCTIONAL TECHNOLOGY}

Most improvement efforts to incorporate instructional technology in the classroom consistently disregard the role of the teacher (Cuban, 2003). However, today's classroom teachers and instructional designers have access to readily available production tools that can incorporate existing pedagogies and curriculums into the domain of online multimedia instruction. Screen-capture instructional technology produces in-house digital lessons for online multimedia learning by infusing speech with dynamic illustrations of enhanced graphics and moving images. For example, using a personal computer or a digital whiteboard, an instructor using screen-capture software can record all of his/her digital screen movements or board markings while simultaneously adding their own voice instruction. 
Screen-capture instructional technology augments a teacher's live lesson into a digital media format. The ensuing multimedia lesson becomes a cognitive tool that supports, guides, and mediates the cognitive processes of learners (Kong, 2011). These online lessons created by teachers for their students are frequently referred to as vodcasts by educators (Walker, Cotner, \& Beerman, 2011). A teacher's entire multimedia curriculum can be made available to students outside the school as a flipped classroom model or accessed inside the blended classroom. However, unlike canned or prepackaged online lessons, the teacher's content knowledge can be sustained. Screen-capture instructional technology used for the blended learning environment also maintains the classroom teacher's live one-to-one instructional support and utilizes the added learning benefits from the interactive classroom experience.

\section{COGNITIVE THEORY OF MULTIMEDIA LEARNING}

The cognitive theory of multimedia learning (CTML) provides instructional practitioners strategies on how words, images, and language can be integrated within multimedia instruction (Mayer, 2001). The theoretical framework behind Mayer's multimedia research can be found in Paivio's dual coding theory that suggested there are two separate cognitive subsystems, a verbal system for processing language and a nonverbal system for nonlinguistic stimulus (Paivio, 1986). Three areas of study in the CTML include the multimedia principal, which analyzes how the brain separately processes audio and visual information, the cognitive load theory, which addresses learners' limited working memory, and the active processing system, that anticipates a student's active learning capacity (Moreno, 2005). As teachers and instructional designers move classroom practices and curriculums toward asynchronous instruction, CTML can assist practitioners in the development of online and blended instruction.

\section{Active Processing System}

The active processing system provides practitioners a framework for transitioning traditional teaching practices toward online and blended instruction. As a student acquires multimedia instruction, the active processing model suggests the brain actively organizes new information by integrating it with existing knowledge. According to Mayer (2009), students are immersed in active learning as they take-in new knowledge and organize the information into mental representations that are synthesized with previously acquired mental representations. In an attempt to organize incoming multimedia instruction, the learner will select relevant words and pictures, organize them into coherent verbal and pictorial models, and build connections between the verbal and pictorial models with prior knowledge. Based in Wittrock's (1992) generative processes of comprehension theory, teaching is the act of directing students toward their generative 
processes for understanding and the formulation of knowledge. To assist the learner's active processing system, multimedia instruction can deploy various instructional devices including self-referential encoding, a pedagogical agent, and signaling.

\section{Self-Referential Encoding}

Self-referential encoding is based in research that analyzes how personalizing instruction can affect human cognition and schemas. Humans are more conscious of instruction when they are spoken to directly and they learn more deeply when the words in a multimedia presentation are in conversational style rather than formal style (Moreno \& Mayer, 2000). Self-referential encoding is one of the most powerful encoding devices, based on the premise that people learn more when the information being processed relates directly to oneself (Rogers, Kuiper, $\&$ Kirker, 1977). In order to form a bond with learners using a multimedia lesson, self-referential encoding can be deployed. "The self-reference effects . . . support the use of personalized conversations in student communications with pedagogic agents as a cognitive tool to promote meaningful learning" (Moreno \& Mayer, 2000 , p. 730). A classroom teacher has the unique ability to contextualize content and create self-referential instruction for their learners. Unlike prepackaged or canned online instruction, a classroom teacher can incorporate specific current events and locally relevant instruction into a blended learning environment. As suggested by Yong Zhao, each community of learners is different and, therefore, all instruction should be approached in a manner that is relevant both locally and individually (Brown \& Cooper, 2009). Additionally, the teacher's ability to create personalized instruction for a student can transform online instruction into an effective classroom learning environment that is knowledge centered, learner centered, and community centered (Bransford, Brophy, \& Williams, 2000).

\section{Pedagogical Agent}

Research has demonstrated that a pedagogical agent's on-screen voice can improve learning by navigating learners seamlessly through a multimedia lesson (Moreno, Mayer, Spires, \& Lester, 2001). To engage learners effectively in multimedia instruction, online instructional techniques often use a pedagogical agent. Mayer (2005) suggested that social cues in multimedia messages could prime a social response within learners that will then lead to deeper cognitive processing and better problem-solving outcomes. By providing social cues through an instructor's image or voice (Figure 1), students form an attachment or partnership with a teacher's multimedia instruction. Social cues incorporated by a pedagogical agent within a multimedia instruction can lead to improved learning outcomes. Acting as a familiar pedagogical agent within his/her own multimedia lesson, the teacher is able to reduce extraneous cognitive processing by visually and verbally directing learners to relevant material (Mayer, 2009). 


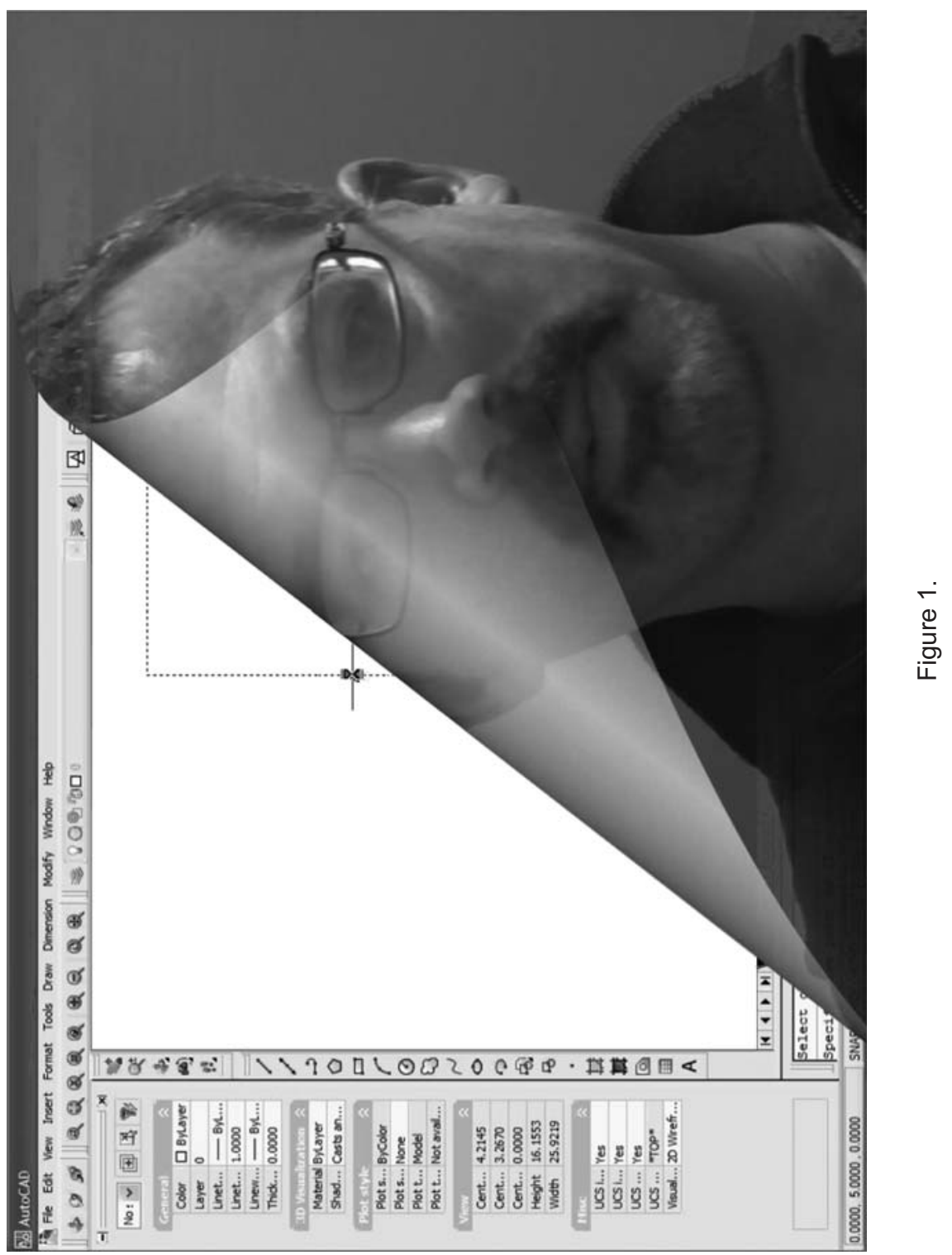




\section{Signaling}

The rationale for multimedia instruction that incorporates moving images of an instructor can be traced back prior to the development of text and language. Man's earliest forms of communication were exhibited in gesture. Gesture theory states that postures and gestures preceded language as a form of communication (Paivio, 2007). Incorporating gestures with auditory narration in a multimedia lesson builds upon the hypothesis that audio and visual information presented together minimizes the overall cognitive load. As students view multimedia instruction, the learner can be signaled by cues toward relevant information, thereby reducing any extraneous load (de Koning, Tabbers, Rikers, \& Paas, 2007). Embedded in the personalized instruction, various signaling principles are employed. By visually directing or signaling students with a pedagogical agent embedded in a multimedia lesson, the instructor is able to provide ongoing engagement that can increase student learning. Yet, "more research is needed to determine the conditions under which the presence of on-screen agents on the screen can foster learning - perhaps through pointing to relevant parts of the screen that the learner might otherwise have difficulty finding" (Mayer, 2009, p. 261).

\section{STATEMENT OF THE HYPOTHESES}

Prior to the first one-to-one personal computing initiatives of the early $1980 \mathrm{~s}$ (Dunleavy, Dextert, \& Heinecket, 2007), researchers have posed the question whether or not computer technology use can effect student achievement in faceto-face classrooms as compared to classrooms that do not use technology (Tamim, Bernard, Borokhovski, Abrami, \& Schmid, 2011). The aim of this study was to determine to what extent, if any, is there a difference in the learning outcomes of secondary students who learn CAD material in multimedia lessons created from a teacher's screen-capture instructional technology when compared to students who learn from traditional textbook instruction. Additionally, the study also sought to determine to what extent, if any, do secondary students prefer learning CAD material from multimedia lessons created from a teacher's screen-capture instructional technology when compared to traditional textbook lessons.

It was hypothesized that secondary students would exhibit equal or significantly higher achievement scores using a teacher's screen-capture technology. Dey, Burn, and Gerdes's (2009) field experiment provided evidence that screencapture instructional technology could successfully embed a pedagogical agent in a college level multimedia lesson. A significant difference in mean scores $(F=9.02, D F=1, p=.00)$ was demonstrated by the screen-capture group $(M=1.30)$ when compared to the live lecture group's mean scores $(M=.92)$. Additionally, Lai, Tsai, and Yu (2011) had similar results in a quasi-experiment of 
adult algebra students. The screen-capture group increased achievement mean scores $(M=70.65)$ as compared to the teacher's live PowerPoint presentation $(M=62.95)$ using a pretest/posttest, $F(1,88)=4.22, p<.05$. In both cases, the means testing revealed a significant difference in scores in favor of the screencapture groups.

Though a post-secondary experiment (Folkestad \& DeMiranda, 2002) using screen-capture participants failed to provide a significant difference in mean scores between the screen-capture subjects $(M=4.08)$ and textbook subjects $(M=4.30)$, the results appear a limitation of the viewing hardware, as suggested by the students' complaints, rather than the screen-capture technology. Using high-speed networks found throughout modern public schools, it was anticipated that limitations of the previous CAD experiment could be overcome. Ongoing advancements in standard computer processors and video graphic cards also create a formidable learning environment for multimedia instruction. Unlike Folkestad et al.'s (2002) experiment where students expressed frustration with the technology, it was speculated that dual monitors would also reduce the learner's cognitive load as they seamlessly switched back and forth between the screen-capture multimedia lesson and the CAD software application.

\section{METHOD}

\section{Participants}

The sample was comprised of 53 California secondary students enrolled in a level one computer aided design (CAD) class. Two students were unable to complete the posttest due to illness, so their pretest scores and surveys were not included in the study. Participants were drawn from a comprehensive high school in California serving just over 1,200 students. In addition to the traditional and college preparatory curriculum, the high school offers technical job training skills through the state's Regional Occupational Program (ROP). Among the broad range of the high school's ROP curriculum, CAD classes were offered as an elective for students who were 16 years of age or older. Students were selected from the secondary school's ROP level one CAD elective. For the 2009-2010 academic school year, the school's guidance counselor randomly assigned each of the level one CAD students into two separate classes using Aeries Student Information System Software. The ethnicity of the 51 students consisted of $72 \%$ White (non-Hispanic) students, 20\% Hispanic students, 4\% African-American students, $2 \%$ Asian students, and $2 \%$ Indian students.

\section{Apparatus}

The high school's computer lab consisted of 36 desktop computers, each with two gigabytes of RAM, Windows XP operating system, and two 17" monitors. An 
additional monitor and corresponding graphics card were added to each computer prior to the study in hopes of enabling students to watch the screen-capture audiovisual instruction on one monitor while they completed the CAD lesson on the other monitor. Students were able to stream the Windows Media Video files from the computer lab's remote classroom server. Individual audio headphones were attached to each computer enabling each screen-capture group participant to hear only their own audio instruction from the multimedia lesson.

\section{Instruments}

Students were administered a pretest-posttest created from the textbook Exercise Workbook for Beginning AutoCAD (Shrock, 2005). This textbook was also chosen because of its simple lessons and step-by-step instructional pacing that easily transferred to the NetOp screen-capture software. The pretest-posttest evaluation (Figure 2) was created from the workbook's Lesson 7 and Lesson 14 (Figure 3), incorporating six learning objectives plus a dimensioning tool function. Though dimension was not specifically a learning objective in the workbook lesson, dimensions appeared predominantly in the lessons and it was therefore added. Additionally, when an object is copied and rotated in AutoCAD, the results in the pretest-posttest activity were identical to the mirror tool function. As a result, copy and rotate were represented solely as mirror in the results section. The pretest-posttest assessment categories were stretch, mirror, fillet, and dimension.

\section{Design and Procedure}

This study used a quasi-experimental research design to measure academic achievement on secondary students learning from a teacher's screen-capture multimedia instruction compared to students learning from the same instruction, but presented from a textbook. A two-group experimental pretest-posttest study was used to compare the results from the textbook and screen-capture instructional methodology. The textbook group used a standard textbook, while the screen-capture group used screen-capture multimedia instruction. The first 20 minutes of each class period was devoted exclusively to the study. Both the textbook and screen-capture groups met over a 1-week period in the CAD lab for three 50-minute classes and one 95-minute class.

On the first day of the study, both the textbook group and screen-capture group were given the pretest activity. Over the following 3 days, both groups were provided a new lesson based in the workbook activities. The traditional textbook students (referred hereafter as the textbook group) were given photocopies of the workbook's Lesson 7 and Lesson 14. The screen-capture multimedia students (referred hereafter as the screen-capture group) used the same lesson objectives as the textbook group, but in a multimedia format (Figure 4) with the instructor's image and audio narration embedded in the lesson acting as a familiar pedagogical agent. Upon completion of the pretest-posttest activity, a student survey (Figure 5) 


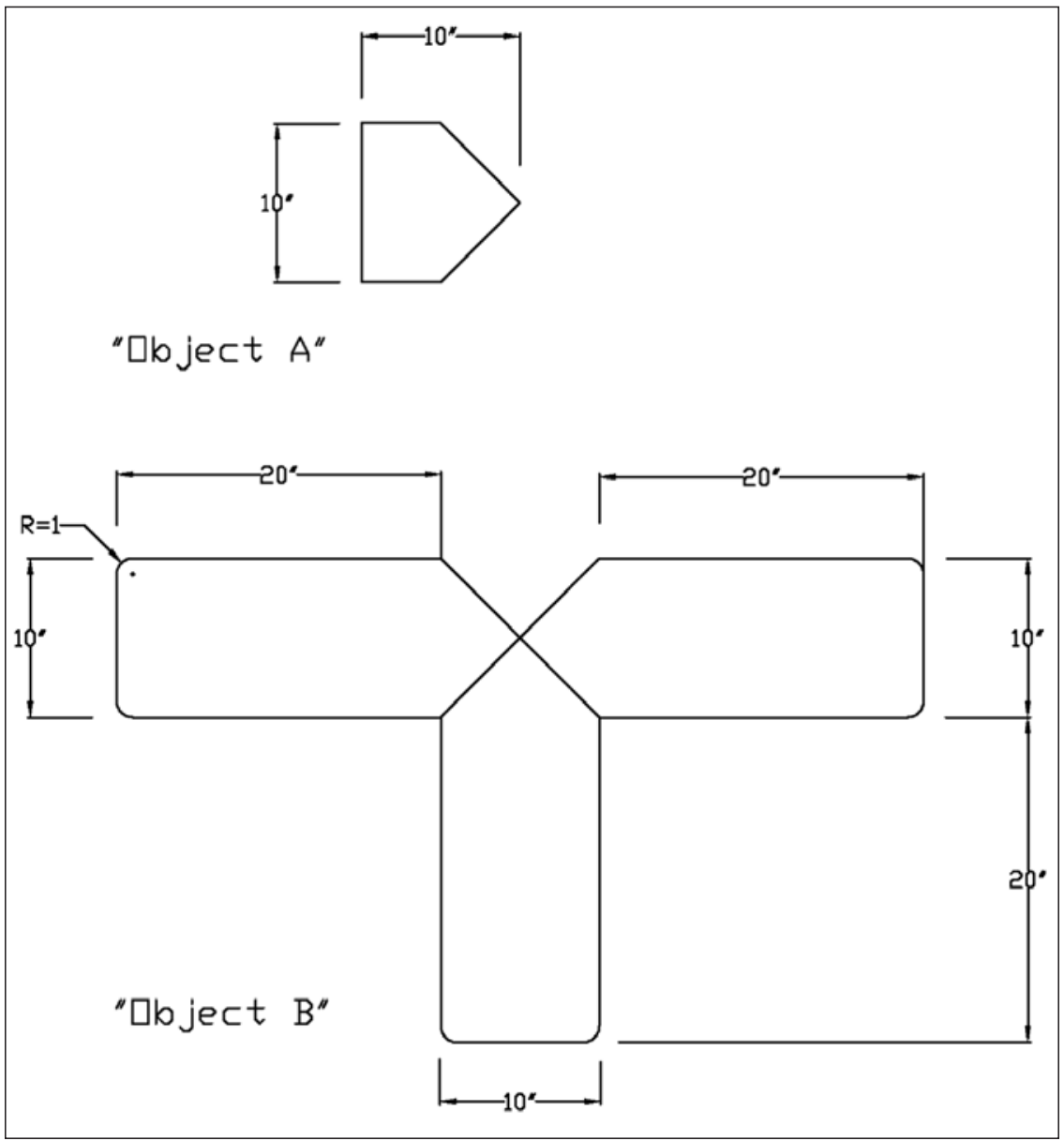

Figure 2. Pretest-Posttest.

Using Auto-CAD, open the file "pretest-posttest.dwg."

Stretch, mirror, and fillet "Object A" so as to create "Object B."

Save your completed work as "yourname_pretest-posttest.dwg."

was administered to assess the favorability of the textbook lesson and screencapture multimedia instruction.

Threats to internal validity were minimized by ensuring the two conditions were equal with the duration of instructional time, content, computer lab, instruments, and classroom instructor. The experiment differed only by how the CAD curriculum was presented to the students. Both the screen-capture group and textbook group participants were not able to receive assistance from the instructor, 


\section{SCALE}

The SCALE command is used to make objects larger or smaller proportionately. You may scale using a scale factor or a reference length. You must also specify a base point. Think of the base point as a stationary point from which the objects scale. It does not move.

1. Select the SCALE command using one of the following:

\section{TYPE $=$ SCALE}

PULLDOWN $=$ MODIFY $/$ SCALE

TOOLBAR $=$ MODIFY

SCALE FACTOR

Command:_scale

2. Select objects: select the object(s) to be scaled

3. Select objects: select more object(s) or <enter> to stop

4. Specify base point: select the stationary point on the object

5. Specify scale factor or [Copy/Reference]: type the scale factor <enter>

If the scale factor is greater than 1 , the objects will increase in size.

If the scale factor is less than 1 , the objects will decrease in size.

\section{REFERENCE}

Command: scale

2. Select objects: select the object(s) to be scaled

3. Select objects: select more object(s) or <enter $>$ to stop

4. Specify base point: select the stationary point on the object

5. Specify scale factor or [Copy/Reference]: select Reference

6. Specify reference length $\langle 1\rangle$ : specify a reference length

7. Specify new length: specify the new length

COPY creates a duplicate of the selected object. The duplicate is directly on top of the original. The duplicate will be scaled. The Original remains the same.

Figure 3. SCALE command. 


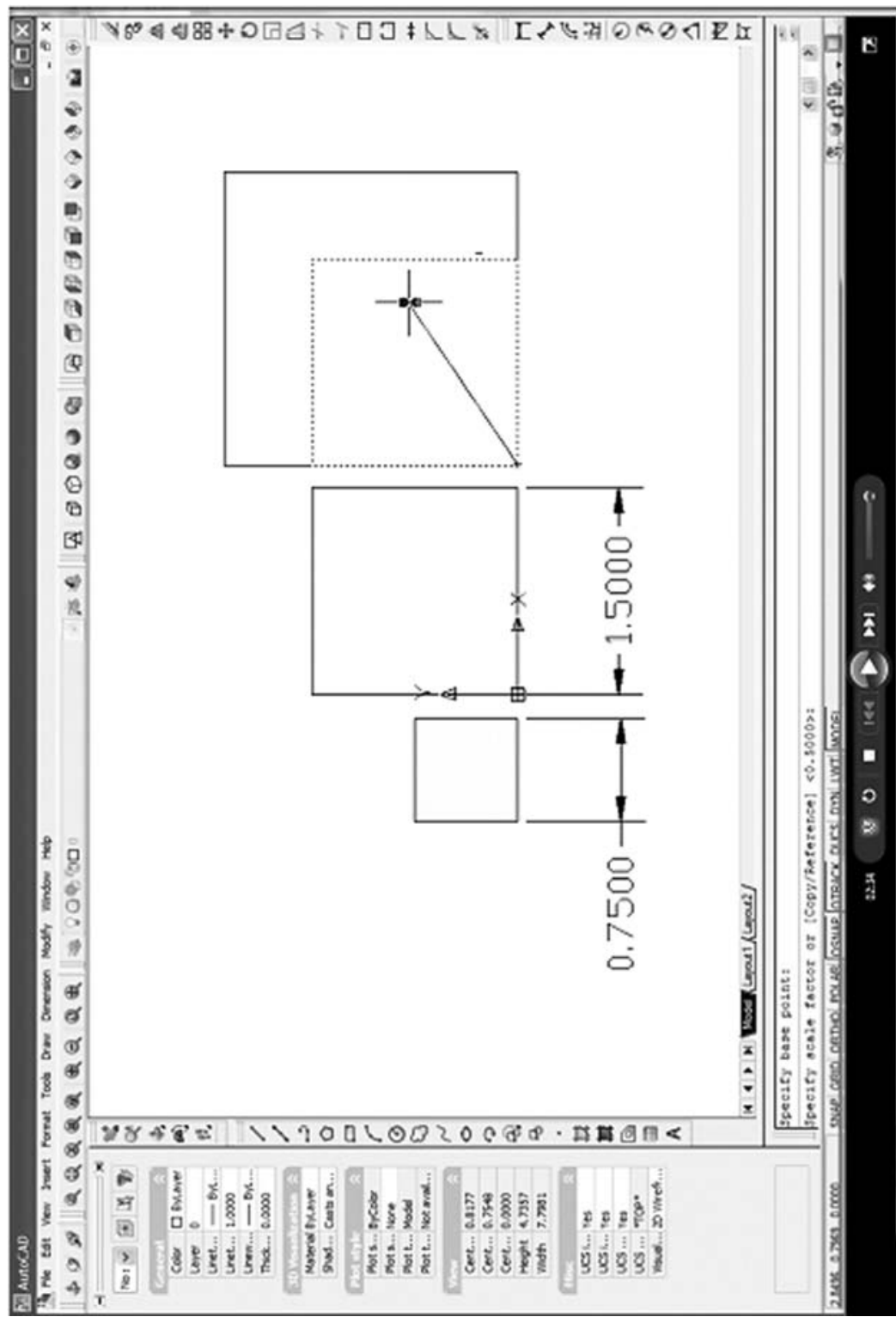

+்
음
몬 


\section{CAD Activity Survey}

A. You have completed four days of AutoCAD instruction and testing. During these activities, you were asked to follow along with a set of instructions. Circle which type you used.

\section{Written Text Audio \& Video}

B. Were the instructions hard to follow? Circle your level of difficulty with the instruction.

1 = too easy $/ 2=$ easy $/ 3=$ O.K. $/ 4=$ hard $/ 5=$ impossible

$\begin{array}{lllll}1 & 2 & 3 & 4 & 5\end{array}$

C. Did the instruction provide you with enough information? Circle the level of information.

$1=$ not nearly enough $/ 2=\mathrm{a}$ little $/ 3=$ just right $/ 4=\mathrm{a}$ lot $/ 5=$ too much

$\begin{array}{lllll}1 & 2 & 3 & 4 & 5\end{array}$

D. Were there problems that made it difficult to learn? Circle the level of problems.

$1=$ none $/ 2$ = a few $/ 3=$ fair amount $/ 4=$ a lot $/ 5=$ too many

$\begin{array}{lllll}1 & 2 & 3 & 4 & 5\end{array}$

E. If there were problems, what caused them?

F. If there were any way, how would you improve the lessons?

G. If you had to learn new CAD material, which method would you prefer? Circle one.

Written Text Audio \& Video

H. Why do you prefer the above method of learning new material?

Figure 5. 
interact with fellow classmates, or access any additional materials. To ensure the CAD instrument was reliable, both subjects used a curriculum developed from a nationally adopted high school workbook recommended by Autodesk, the software's manufacturer. The control group subjects read the workbook lessons, while the screen-capture group watched and listened to the workbook lessons in a multimedia format. For the screen-capture group's multimedia lessons, the instructor followed the CAD workbook lessons exactly as written in the textbook and simultaneously captured the computer's screen movements with the screencapture software. Precise audiovisual synchronization was assured using Sony Vegas Pro's multimedia editing software that ultimately combined the teacher's speech with the captured moving images and graphics.

External controls for the quasi-experiment included using the pretest achievement scores as a covariant to statistically control for the non-random assignment of participants. The pretest-posttests, with random identifiers replacing student names, were scored by a college-level drafting instructor. This instructor was provided a scoring rubric (Figure 6) and was blind to the group (textbook or screencapture). To ensure a reliable scoring procedure, the pretest/posttest scoring rubric measured testing results by summing the aggregate of the tool function tasks.

\section{RESULTS}

When looking at the overall total scores, students learning CAD from computer-based multimedia instruction had significantly higher posttest scores than those learning from the traditional textbook instruction. The results indicated an increase in knowledge acquisition and transfer for the screen-capture group. Two measures, Partial Eta Squared (partial $\eta^{2}$ ) and Cohen's $d$ were calculated to measure the magnitude of the effect of the multimedia instruction. For Partial Eta Squared, 0.0099 constitutes a small effect, 0.0588 a medium effect, and 0.1379 a large effect (Cohen, 1988), and for Cohen's $d$, less than .1 is trivial, .1 to .3 is considered small, .3 to .5 is moderate, and over .5 is considered a large effect size.

A one-way ANCOVA was calculated using prior knowledge from the pretest as a covariate to examine the effect of prior knowledge on the posttest results (Table 1). Though both the screen-capture and textbook group's total posttest scores improved over the total pretest scores, the total scores on the posttest were significantly higher for students in the screen-capture group $(M=9.71)$ than those in the textbook group $(M=7.83), F(1,48)=4.79, p<.05$, partial $\eta^{2}=.09$. The ANCOVA confirmed that prior knowledge did not significantly affect the posttest results, and with a Partial Eta Squared of .09 for the main effect of group membership (screen-capture vs. textbook) indicating a moderate effect size.

When the total scores were broken down by individual task (Table 2), the greatest improvement was by the CAD students in the screen-capture group on the mirror and fillet tasks, with scores significantly related to instructional style, $F(1,48)=6.03, p<.05$, partial $\eta^{2}=.11$ and $F(1,48)=7.33, p<.05$, 
SCREEN-CAPTURE INSTRUCTIONAL TECHNOLOGY / 221

\begin{tabular}{|c|c|c|c|c|c|c|c|c|c|}
\hline \multirow{5}{*}{ 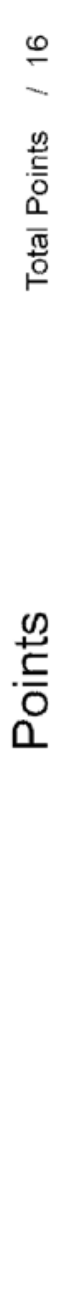 } & 0 & 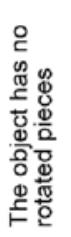 & 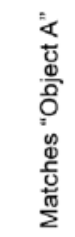 & 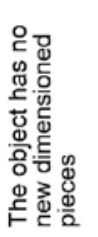 & 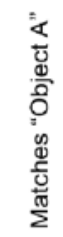 & 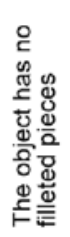 & 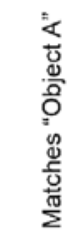 & 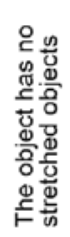 & 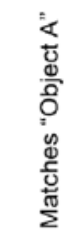 \\
\hline & $\leftarrow$ & 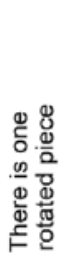 & 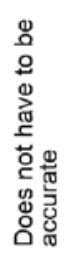 & 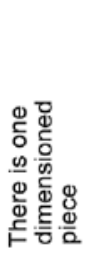 & 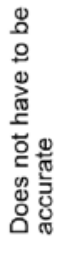 & 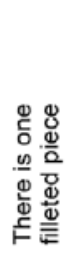 & 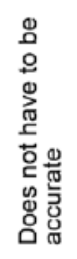 & 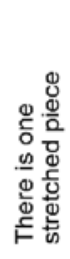 & 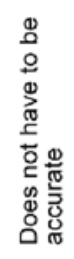 \\
\hline & $N$ & 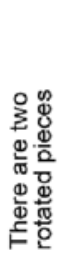 & 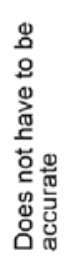 & 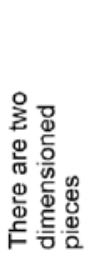 & 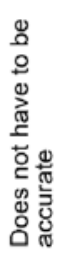 & 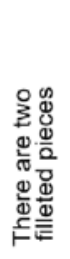 & 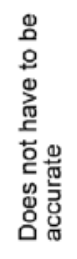 & 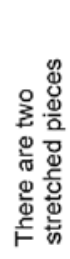 & 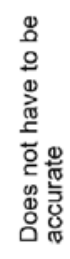 \\
\hline & $m$ & 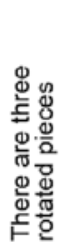 & 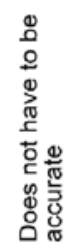 & 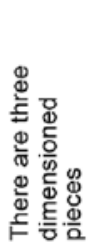 & 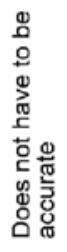 & 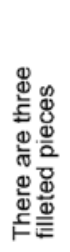 & 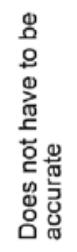 & 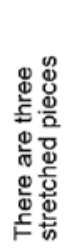 & 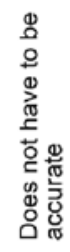 \\
\hline & $\checkmark$ & 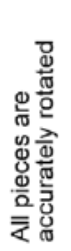 & 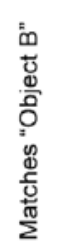 & 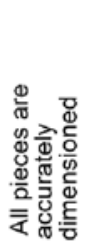 & 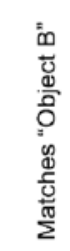 & 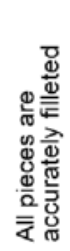 & 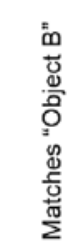 & 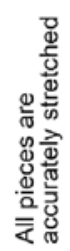 & 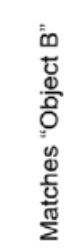 \\
\hline \multicolumn{2}{|c|}{ 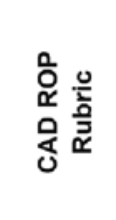 } & \multicolumn{2}{|c|}{$\begin{array}{l}\frac{1}{ \pm} \\
\frac{\pi}{0} \\
\frac{2}{2} \\
4 \\
4\end{array}$} & \multicolumn{2}{|l|}{ 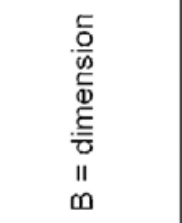 } & \multicolumn{2}{|c|}{ 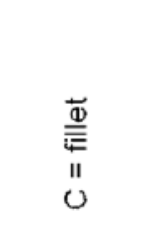 } & \multicolumn{2}{|c|}{$\begin{array}{l}\frac{5}{0} \\
\frac{0}{2} \\
\frac{\omega}{5} \\
11 \\
0 \\
0\end{array}$} \\
\hline
\end{tabular}

0
$\frac{0}{3}$
$\frac{0}{5}$
$i \frac{7}{4}$ 
Table 1. CAD Pretest and Posttest

\begin{tabular}{lcccc}
\hline Textbook or Screen-capture & $n$ & $M$ & SD & $\begin{array}{c}\text { Std. Error } \\
\text { Mean }\end{array}$ \\
\hline Pretest & & & & \\
$\quad$ Textbook Group & 26 & 3.27 & 3.01 & .58 \\
$\quad$ Screen-capture Group & 25 & 3.56 & 2.71 & .54 \\
& & & & \\
Posttest & & & & \\
$\quad$ Textbook Group & 26 & 7.77 & 3.95 & .77 \\
$\quad$ Screen-capture Group & 25 & 9.78 & 2.44 & .49 \\
\hline
\end{tabular}

Table 2. Means for Subtest and Total Scores

\begin{tabular}{lccc}
\hline & \multicolumn{2}{c}{ Mean scores } \\
\cline { 2 - 3 } & Screen-capture & Textbook & $F$ \\
\hline Total & 9.71 & 7.83 & $4.79^{*}$ \\
Mirror & 2.90 & 2.41 & $6.03^{*}$ \\
Stretch & 2.38 & 2.09 & $.40^{a}$ \\
Fillet & 3.23 & 1.84 & $7.33^{*}$ \\
Dimension & 1.28 & 1.42 & .19 \\
\hline
\end{tabular}

aThe covariate of pretest scores were significant, while the overall $F$ for the group was not significant.

${ }^{*} p<.05$.

partial $\eta^{2}=.13$. With the CAD skill of stretch, the covariate posttest score was significant, while the overall $F$ for group was not significant, $F(1,48)=.40$, $p>.05$, partial $\eta^{2}=.008$, and so all students improved on this skill, regardless of their group. Conversely, scores on the dimension function were found to be higher but not significant in the textbook group's posttest results when compared to the screen-capture group, $F(1,48)=.19, p>.05$, partial $\eta^{2}=.004$. These results will be further discussed in the discussion section.

To examine the student's favorability and satisfaction rate for each method of instruction, a student survey was conducted (Figure 5). It should be noted that both the textbook and screen-capture groups had prior experience earlier in the school year learning from both instructional methods within the CAD class. After the posttest study, each student anonymously self-reported his or her level 
of satisfaction across domains of level of difficulty of instructions, if the lesson provided enough information, and if there were problems that made it difficult to learn, using Likert rating scales (Table 3). The $t$-tests indicated that, for the difficulty of the instructions (question $B)$, the textbook $(M=2.92, S D=0.10)$ and screen-capture group $(M=2.57, S D=0.74)$ difference was not significant, $t=.152, p>.05, d=.66$. Cohen's effect size value $(d=.66)$ for "level of difficulty of the instructions" suggested a high practical significance. On question $C$, the textbook instruction group wanted more information $(M=3.76, S D=0.66)$, compared to the screen-capture group, which had higher rates of participants reporting they had just right or a lot of information $(M=3.10, S D=.74), t=3.37$, $p<.001, d=.94$. Cohen's effect size value $(d=.94)$ for "amount of information provided" suggested a high practical significance. For question $D$, there were no significant differences between the amount of problems from the textbook $(M=2.20, S D=1.15)$ and audiovisual instruction $(M=2.43, S D=1.07)$. A crosstabulation was conducted to examine preference in instructional methodology (question $G$; Table 4), with both groups overwhelmingly favoring the audiovisual pedagogy $(88.2 \%)$ compared to learning from the written text (11.8\%). Of the textbook group participants, $79.2 \%$ favored the audiovisual instruction to written text, while $96.3 \%$ of variable group participants preferred the audiovisual instruction.

\section{DISCUSSION}

\section{Implication for Practice}

Computer-based instruction is rapidly expanding for secondary schools in the United States. School districts throughout the nation are incorporating new

Table 3. Difficulty Survey of Instruction

\begin{tabular}{lccc}
\hline & \multicolumn{2}{c}{ Mean scores } & \\
\cline { 2 - 3 } & Screen-capture & Textbook & $F$ \\
\hline $\begin{array}{l}\text { B. Were the instructions hard } \\
\text { to follow? }\end{array}$ & 2.57 & 2.92 & 2.09 \\
$\begin{array}{l}\text { C. Did the instruction provide } \\
\text { enough information? }\end{array}$ & 3.11 & 3.76 & $0.06^{*}$ \\
$\begin{array}{l}\text { D. Were there any problems } \\
\text { with the lesson that made } \\
\text { it difficult to learn? }\end{array}$ & 2.43 & 2.2 & \\
\hline
\end{tabular}

${ }^{*} p<.001$. 
Table 4. Crosstabulation of Student Preference

\begin{tabular}{lrrr}
\hline & \multicolumn{2}{c}{ Instrument } & \\
\cline { 2 - 3 } & Textbook & Screen-capture & Total \\
\hline $\begin{array}{l}\text { G. If you had to learn new CAD } \\
\text { material, which method would }\end{array}$ & & & \\
$\begin{array}{l}\text { you prefer? } \\
\quad \text { Written text }\end{array}$ & $5(20.8 \%)$ & $1(3.7 \%)$ & 6 \\
$\quad \begin{array}{l}\text { Audiovisual } \\
\text { Total }\end{array}$ & $19(79.2 \%)$ & $26(96.3 \%)$ & 45 \\
\hline
\end{tabular}

Note: Percents are within each group.

instructional technologies, such as online classes, with little assurance student learning will increase (Figlio et al., 2010). As purported by the U.S. Department of Education's meta-analysis, “educators making decisions about online learning need rigorous research examining the effectiveness of online learning for different types of students and subject matter as well as studies of the relative effectiveness of different online learning practices" (USED, 2009, p. 54). However, as noted by Mayer (2009), multimedia learning research is still in its infancy.

Based on the results from this study, a teacher utilizing screen-capture instructional technology to design a blended multimedia curriculum can increase the academic achievement of secondary students. The effect size demonstrated by the total scores shows that $9 \%$ of the variability in posttest scores (a moderate to large effect) can be attributed to either being in the screen-capture or textbook group. Students' scores on individual tasks demonstrated that those receiving screen-capture multimedia instruction performed similarly to textbook instruction on two tasks and significantly better than textbook on the other two more difficult tasks. Though some of the more basic tasks, such as dimensioning and stretching an object, were not significant, these results may suggest that the more complex and difficult the subject matter, the better the multimedia instruction works to increase comprehension. Mayer (2009) suggested that increases in achievement from multimedia instruction assist low-performing students, this research demonstrated that student knowledge acquisition and transfer across all students using multimedia instruction. In the future, Mayer's theory could be examined in a larger sample by stratifying by overall grade point average in order to evaluate the differential benefit of blended multimedia learning.

Results from this study advance Mayer's (2001) CTML by demonstrating that words, images, and language can be successfully integrated into a secondary student's multimedia curriculum. This experiment incorporated a hyper-blended 
learning model where all of the teacher's multimedia lessons were delivered online into the classroom, without the use of any live lectures. Unlike the USED (2009) meta-analysis that suggested increased achievement in blended learning may be due to the additional learning time and supplementary instructional elements, this study controlled for these variables. The screen-capture group participants were not able to ask questions during the experiment from the instructor, classmates, or access additional materials. Contrary to Folkestad et al.'s (2002) screen-capture results and unfavorable survey responses to the viewing technology, this study indicated the student's overall cognitive load was minimized using the dual monitor configuration as the screen-capture subjects viewed the teacher's online instruction while completing the CAD activity. When placed in the context of the accountability requirements for secondary educators, this study suggests that capturing a student's familiar teacher as an online pedagogical agent can be used toward establishing a blended learning environment without radically changing current teaching practices.

\section{Limitations of the Study}

This investigation provides insight into the impact of multimedia/screencapture instruction over the course of 1 week on secondary students. A more lengthy investigation with a larger sample size and expanding the age groups to include K-8 students may provide greater understanding into the potential utility of this type of online learning. Due to the short duration of the study, students could have experienced a potential interactive effect enabling them to remember the pretest exercise; however, the complex nature of the testing material should have had a minimal impact on the research study (Gay, Mills, \& Airasian, 2009). Additionally, this study only measured blended multimedia instruction in comparison to textbook instruction and did not compare blended multimedia learning to purely online multimedia learning.

\section{Future Research and Direction}

With pressures to improve student academic proficiency and the increasing availability of prepackaged online instruction, this investigation demonstrated that secondary students benefit from screen-capture instructional technology when it is successfully transferred into the secondary classroom. Though this study evaluated screen-capture instructional technology in a CAD class, these techniques could be applicable to other mainstream curriculums that use whiteboard-instruction or rely on graphical representations for instruction. A teacher who is dependant on demonstrating new material in front of the classroom could benefit by incorporating this type of asynchronous learning within a blended multimedia learning environment. It would also be noteworthy to test the hypothesis that secondary students using screen-capture instructional 
technology learn at an equal or higher rate on secondary curriculums dependent on textbook instruction including Math, Science, and English.

Not to be dismissed, $45(88.2 \%)$ of the students surveyed in the experiment preferred learning new CAD material using screen-capture instructional technology over the textbook format. The preference results also suggest that the more students used the multimedia instruction, the more they favored the pedagogy. Participants stated that it was easier to learn using multimedia instruction than from reading written instructions. Anecdotally, these students also indicated that they liked being able to watch and listen to the instruction, and many claimed they learned better with computer-based visuals. A few commented that when they used the screen-capture instruction, they were not distracted by other students in the classroom. Other screen-capture group participants stated they could easily hear their teacher's instruction, not like in their traditional classrooms. Considering the students' improved academic achievement and their overwhelming preference for their teacher's blended multimedia curriculum, secondary classroom teachers could successfully reach their students in the digital world they inhabit by incorporating screen-capture instructional technology.

\section{REFERENCES}

Bransford, J., Brophy, S., \& Williams, S. (2000). When computer technologies meet the learning sciences. Journal of Applied Developmental Psychology, 21(1), 59-84.

Brown, S., \& Cooper. D. (2009). No Child Left Behind and global competitiveness: Yong Zhao [Podcast]. Retrieved from http://newlearninginstitute.org/21stcentury education//21 st-century-learning/no-child-left-behind-and-global-competitiveness. html\#

Cesarini, P., Sinn, J., \& Armentano, T. (2006). Distance education at Bowling Green State University: Challenges, opportunities, and promise. Journal of Industrial Technology, 22(4), 1-10.

Christensen, C. M., Horn, M. B., \& Johnson, C. W. (2008). Disrupting class: How innovation will change the way the world learns. New York: McGraw-Hill.

Cohen, J. (1988). Statistical power analysis for the behavior sciences. Hillsdale, NJ: Lawrence Erlbaum.

Cuban, L. (2003). Why is it so hard to get good schools? New York: Teachers College Press.

Dale, C., \& Pymm J. (2009). The iPod as a learning technology. Active Learning in Higher Education, 10(1), 84-96.

de Koning, B., Tabbers, H., Rikers, R., \& Paas, F. (2007). Attention cueing as a means to enhance learning from an animation. Applied Cognitive Psychology, 21(6), 731-746.

Dey, E., Burn, H., \& Gerdes, G. (2009). Bringing the classroom to the web: Effects of using new technologies to capture and deliver lectures. Research in Higher Elucidation, 50(4), 377-393.

Dunleavy, M., Dextert, S., \& Heinecket, W. (2007). What added value does a 1:1 student to laptop ratio bring to technology-supported teaching and learning. Journal of Computer Assisted Learning, 23(5), 440-452. 
Figlio, D. N., Rush, M., Yin, L., \& National Bureau of Economic Research. (2010). Is it live or is it internet?: Experimental estimates of the effects of online instruction on student learning. Cambridge, MA: National Bureau of Economic Research.

Folkestad, J. E., \& DeMiranda, M. A. (2002). Impact of screen-capture based instruction on student comprehension of computer aided design (CAD) software principles. Journal of Industrial Technology, 18(1), 1-7.

Gay, L. R., Mills, G. E., \& Airasian, P. (2009). Educational research: Competencies for analysis and applications (9th ed.). Upper Saddle River, NJ: Pearson Education.

Kingsley, K. V., \& Boone, R. (2008). Effects of multimedia software on achievement of middle school students in an American History class. Journal of Research on Technology in Education, 41(2), 203-222.

Kong, S. (2011). An evaluation study of the use of a cognitive tool in a one-to-one classroom for promoting classroom-based interaction. Computers \& Education, 57(3), 1851-1864.

Lai, Y., Tsai, H., \& Yu, P. (2011). Screen-capturing system with two-layer display for PowerPoint presentation to enhance classroom education. Educational Technology \& Society, 14(3), 69-81.

Mayer, R. E. (2001). Multimedia learning. Cambridge: Cambridge University Press.

Mayer, R. E. (2005). The Cambridge handbook of multimedia learning. New York: Cambridge University Press.

Mayer, R. E. (2009). Multimedia learning (2nd ed.). New York: Cambridge University Press.

Moreno, R. (2005). Multimedia learning with animated pedagogical agents. In R. E. Mayer (Ed.), The Cambridge handbook of multimedia learning (pp. 287-296). New York: Cambridge University Press.

Moreno, R., \& Mayer, R. E. (2000). Engaging students in active learning: The case for personalized multimedia messages. Journal of Educational Psychology, 92(4), 724-733.

Moreno, R., Mayer, R. E., Spires, H. A., \& Lester, J. C. (2001). The case for social agency in computer-based teaching: Do students learn more deeply when they interact with animated pedagogical agents? Cognition and Instruction, 19(2), 177-213.

Paivio, A. (1986). Mental representations: A dual coding approach. New York: Oxford University Press.

Paivio, A. (2007). Mind and its evolution: A dual coding approach. Mahwah NJ: Lawrence Erlbaum.

Picciano, A. G., \& Seaman, J. (2009). K-12 online learning: A survey of U.S. school district administrators. Boston: Sloan Consortium.

Rogers, T. B., Kuiper, N. A., \& Kirker, W. S. (1977). Self-reference and the encoding of personal information. Journal of Personality and Social Psychology, 35(9), 677-688.

Shrock, C. R. (2005). Exercise workbook for beginning AutoCAD. New York: Industrial Press.

Smith, C. (2006). Lecturing by streaming digital video: Blood, sweat, tears and success. In J. O'Donoghue (Ed.), Technology supported learning and teaching: A staff perspective (pp. 309-322). Hershey, PA: Idea Group.

Sweller, J. (2005). Implications of cognitive load theory for multimedia learning. In R. E. Mayer (Ed.), The Cambridge handbook of multimedia learning (pp. 19-30). New York: Cambridge University Press. 
Tamim, R., Bernard, R., Borokhovski, E., Abrami, P., \& Schmid R. (2011). What forty years of research says about the impact of technology on learning: A second-ordermeta-analysis and validation study. Review of Educational Research, 81(1), 4-28.

Telecommunications Act of 1996, Pub. LA. No. 104-104, 110 Stat. 56. (1996). Retrieved from http://www.fcc.gov/telecom.html

U.S. Department of Education (USED). (2009). Evaluation of evidence-based practices in online learning: A meta-analysis and review of online learning studies. Washington, DC: Office of Planning, Evaluation, and Policy Development.

Walker, J., Cotner. S., \& Beerman, N. (2011). Vodcasts and captures: Using multimedia to improve student learning in introductory biology. Journal of Educational Multimedia and Hypermedia, 20(1), 97-111.

Wittrock, M. (1992). Generative learning process of the brain. Educational Psychologist, $27(4), 531-541$.

Direct reprint requests to:

Jeffrey G. Smith

Educational Leadership Program

Saint Mary's College of California

1928 Saint Mary's Road

Moraga, CA 94556

e-mail: jeffrey@brighteyes.com 